\title{
Mono and trinuclear lanthanide complexes of 13-membered tetraaza macrocycle: Synthesis and characterization
}

\author{
B SINGH* and V L SINGH \\ Department of Chemistry, Banaras Hindu University, Varanasi 221 005, India
}

MS received 19 September 1998; revised 28 June 1999

\begin{abstract}
The reaction of 1,8-diamino-3,6-diazaoctane and diethyl malonate in dry methanol yielded a 13-membered macrocycle. Complexes of the type $\left[\mathrm{Ln}(\operatorname{tatd}) \mathrm{Cl}_{2}\right.$ $\left.\left(\mathrm{H}_{2} \mathrm{O}\right)_{3}\right] \mathrm{Cl}\left[\mathrm{Ln}^{\mathrm{III}}=\mathrm{La}, \mathrm{Pr}, \mathrm{Nd}, \mathrm{Sm}, \mathrm{Eu}, \mathrm{Gd}, \mathrm{Tb}, \mathrm{Dy} ;\right.$ tatd $=1,5,8$, 11-tetraazacyclotridecane-2,4-dione] have been synthesized by template condensation. The complex [ $\mathrm{La}($ tatd $\left.) \mathrm{Cl}_{2}\left(\mathrm{H}_{2} \mathrm{O}\right)_{3}\right] \mathrm{Cl}$ in methanol was reacted with lanthanide chlorides to yield the trinuclear complexes of type $\left[2\left\{\mathrm{La}(\operatorname{tatd}) \mathrm{Cl}_{2}\left(\mathrm{H}_{2} \mathrm{O}\right)_{3}\right\} \mathrm{LnCl}_{3}\right] \mathrm{Cl}_{2}\left[\mathrm{Ln}^{\mathrm{III}}=\mathrm{La}, \mathrm{Pr}\right.$, $\mathrm{Nd}, \mathrm{Sm}, \mathrm{Eu}, \mathrm{Gd}, \mathrm{Tb}, \mathrm{Dy}$ ]. The chemical compositions of mono and trinuclear complexes have been established on the basis of analytical, molar conductance, electrospray (ES) and fast atom bombardment (FAB) mass data. In mononuclear complexes the $\mathrm{Ln}^{3+}$ jon is encapsulated by four ring nitrogens and in trimetallic complexes the exo-carbonyl oxygens of two mononuclear units coordinate to the $\mathrm{Ln}^{3+}$ ions resulting in a polyhedron around the lanthanide ions. Thus the macrocycle is bonded in a tetradentate fashion in the former complexes and hexadentate in the latter. The coordination number nine around the encapsulated $\mathrm{Ln}^{3+}$ and seven around the exo-oxygen bonded $\mathrm{Ln}^{3+}$ ions are established. The symmetry of the ligand field around the metal ions is indicated from the emission spectra.
\end{abstract}

Keywords. Tetraaza macrocyclic complexes; lanthanide complexes; macrocyclic lanthanide complexes.

\section{Introduction}

The coordination chemistry of macrocyclic ligands is a fascinating research area. The transition and lanthanide metal ions have been used as templates in the synthesis of 10 , $12,13,14$ and 18 membered polyazamacrocyclic complexes ${ }^{1-5}$. The macrocycles impose unusual coordination geometry on a range of the metal ions. The lanthanide macrocyclic complexes may be useful in phosphate ester hydrolysis as effective catalysts ${ }^{6}$ in the transesterification of RNA. The ferrites and chromites atom based inorganic ferromagnetic materials are used for storage and processing of information in almost such devices as computers and tapes. The minimum dimension of such devices is the range of micrometer. Therefore, new materials and new processes are to be searched for developing molecular level magnetic devices ${ }^{7-9}$. This may be achieved by synthesizing molecular assemblies by bridging the metal ions of the same or different types through organic ligands to impose cooperative magnetic effects. The molecular magnets should have high $T_{C}$ or $T_{N}$ preferably around the room temperature and a large coercive field.

*For correspondence 
In this paper we report synthesis and characterization of the complexes $\left[\mathrm{Ln}(\operatorname{tatd}) \mathrm{Cl}_{2}\left(\mathrm{H}_{2} \mathrm{O}\right)_{3}\right] \mathrm{Cl}$ and $\left[2\left\{\mathrm{La}(\right.\right.$ tatd $\left.\left.) \mathrm{Cl}_{2}\left(\mathrm{H}_{2} \mathrm{O}\right)_{3}\right\} \mathrm{LnCl}_{3}\right] \mathrm{Cl}_{2}$.

\section{Experimental}

\subsection{Materials}

1,8-Diamino-3, 6-diazaoctane (E. Merck), diethyl malonate (Sisco Research Lab Pvt. Ltd.), lanthanide chlorides (Indian Rare Earth Ltd., Kerala) and other chemicals of analytical reagents grade were used.

\subsection{Preparation of the macrocycle}

The macrocycle 1,5,8,11-tetraazacyclotridecane-2,4-dione was prepared using the following procedure ${ }^{10}$. 1,8-Diamino-3,6-diazaoctane $\left(0.75 \mathrm{~cm}^{3}, 5 \mathrm{mmol}\right)$ was added dropwise to diethyl malonate $\left(0.76 \mathrm{~cm}^{3}, 5 \mathrm{mmol}\right)$ in dry ethanol $\left(50 \mathrm{~cm}^{3}\right)$ with continuous stirring. The reaction solution was refluxed for $-120 \mathrm{~h}$ and was reduced to $-5 \mathrm{~cm}^{3}$ in rotary evaporator. The white compound crystallized after slow evaporation in 3-4 days. It was filtered and washed with cold dry ethanol. It was recrystallized from ethanol and dried under reduced pressure. Yield, $0.16 \mathrm{~g}(15 \%) ;$ m.p. $183-5^{\circ} \mathrm{C}$ (uncorrected). Found: C, $50.40 ; \mathrm{H}, 8.45 ; \mathrm{N}, 26.14 ; \mathrm{C}_{9} \mathrm{H}_{18} \mathrm{~N}_{4} \mathrm{O}_{2}$ calcd: $\mathrm{C}, 50.45 ; \mathrm{H}, 8.46 ; \mathrm{N}, 26.14$. The compound was characterized by mass, NMR and IR spectra. In the mass spectrum (figure 1) molecular ion $\left(\mathrm{M}^{+}\right)$and base $\left[\mathrm{NHCH}_{2} \mathrm{CH}_{2}\right]^{+}$peaks appear at $\mathrm{m} / \mathrm{z}=214$ and $\mathrm{m} / \mathrm{z}=44$, respectively. Fragments are given in scheme 1. The proton NMR spectrum of the compound exhibits signals at $\delta 2.24(s, 2 \mathrm{H},-\mathrm{NH}), 2.72\left(m, 8 \mathrm{H}, \mathrm{CH}_{2}-\mathrm{N}-\mathrm{CH}_{2}\right), 3.0(s, 2 \mathrm{H}$, $\left.\mathrm{CO}-\mathrm{CH}_{2}-\mathrm{CO}\right), 3 \cdot 14\left(m, 4 \mathrm{H}, \mathrm{CO}-\mathrm{N}-\mathrm{CH}_{2}\right)$ and $8.02(b, 2 \mathrm{H}, \mathrm{C}-\mathrm{NH}-\mathrm{CO})$.

\subsection{Synthesis of complexes [ $\mathrm{Ln}($ tatd $\left.) \mathrm{Cl}_{2}\left(\mathrm{H}_{2} \mathrm{O}\right)_{3}\right] \mathrm{Cl}$}

1,8-Diamino-3,6-diazaoctane $(1 \mathrm{mmol})$ was added to a methanol solution $\left(7.5 \mathrm{~cm}^{3}\right)$ of diethyl malonate $(1 \mathrm{mmol})$ and refluxed for $\sim 3 \mathrm{~h}$. The solution turned reddish violet. A

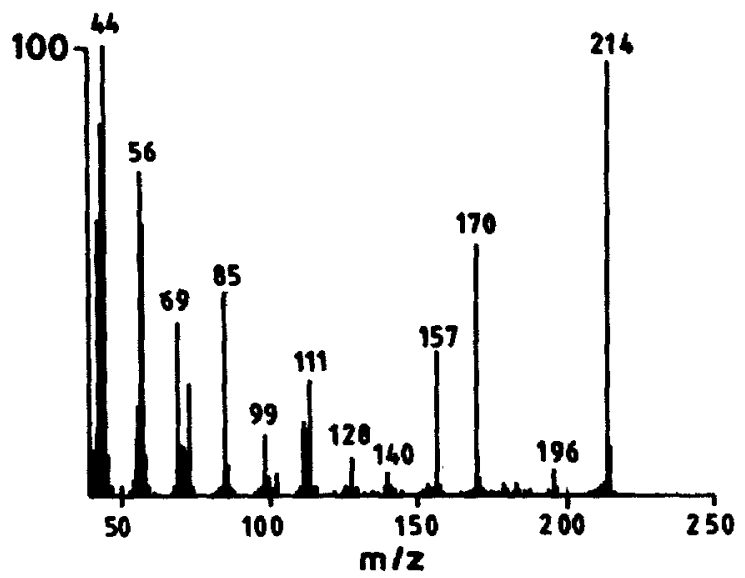

Figure 1. Mass spectrum of free macrocycle. 


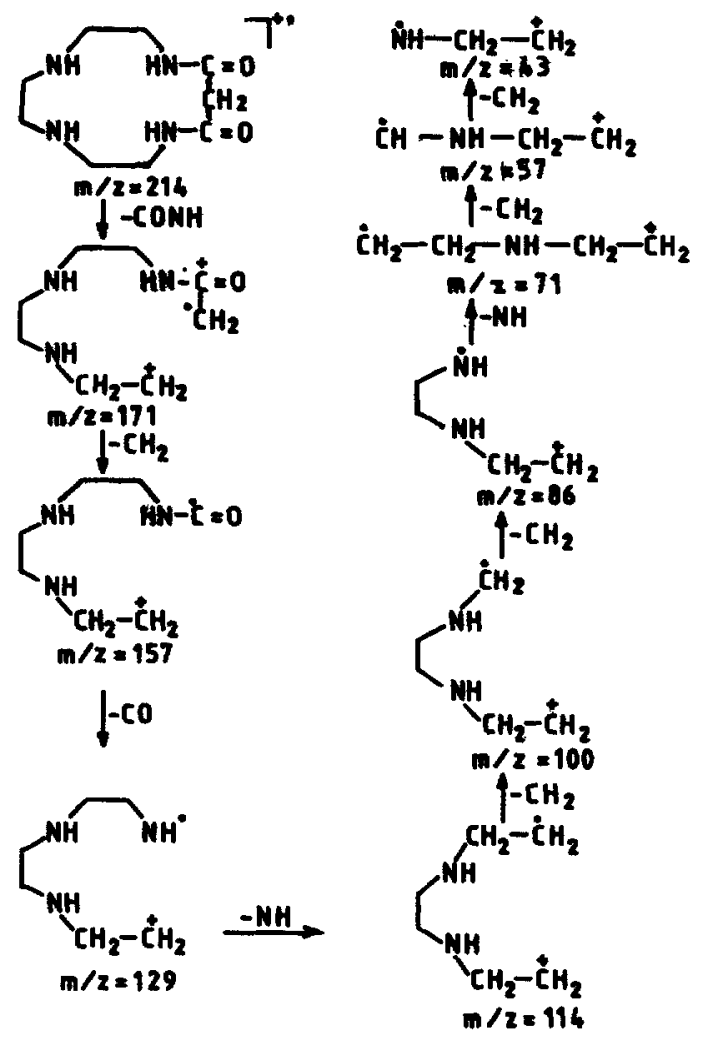

Scheme 1. Mass fragmentation pattern of tatd.

solution of lanthanide chloride $(1 \mathrm{mmol})$ in dry methanol $\left(30 \mathrm{~cm}^{3}\right)$ was added slowly to the above refluxing reaction solution with continuous stirring over a period of $1 \mathrm{~h}$. The reaction solution was concentrated and the gummy solid was obtained which was rubbed with acetonitrile several times to crystallize the compounds. It was filtered, washed with acetonitrile and ethanol mixture $(3: 1)$ and dried under reduced pressure. The yield and melting point of compounds are given in table 1.

\subsection{Synthesis of trinuclear complexes $\left[2 / \mathrm{La}(\right.$ tatd $\left.) \mathrm{Cl}_{2}\left(\mathrm{H}_{2} \mathrm{O}\right)_{3} / \mathrm{LnCl}_{3}\right] \mathrm{Cl}_{2}$}

The compound [ $\mathrm{La}$ (tatd) $\left.\mathrm{Cl}_{2}\left(\mathrm{H}_{2} \mathrm{O}\right)_{3}\right] \mathrm{Cl}(0.51 \mathrm{~g}, 1 \mathrm{mmol})$ was dissolved in dry methanol $\left(30 \mathrm{~cm}^{3}\right)$ and to this solution of $\mathrm{LnCl}_{3} \cdot \mathrm{nH}_{2} \mathrm{O}(1 / 2 \mathrm{mmol})$ in dry methanol $\left(10 \mathrm{~cm}^{3}\right)$ was added slowly. The solution was refluxed for $2 \mathrm{~h}$ and concentrated resulting in a gummy solid. It was macerated with acetonitrile to give the compound. It was filtered and washed with acetonitrile and ethanol mixture $(3: 1)$ and dried under reduced pressure. The yield and melting point of the compounds are given in table 1 . 
Table 1. Analytical data, colour, melting point, molar conductance and magnetic moment of mono and trinuclear complexes of tatd.

\begin{tabular}{|c|c|c|c|c|c|c|c|}
\hline \multirow{2}{*}{$\begin{array}{l}\text { Complex, colour, } \\
\text { M.P. }\left({ }^{\circ} \mathrm{C}\right) \text {, } \\
\text { yield }(\%)\end{array}$} & \multicolumn{5}{|c|}{ Found (calcd.) \% } & \multirow{2}{*}{$\begin{array}{l}\text { Molar } \\
\text { condu- } \\
\text { ctance } \Omega \\
\mathrm{cm}^{2} \mathrm{~mol}^{-1}\end{array}$} & \multirow{2}{*}{$\begin{array}{c}\text { Magnetic } \\
\text { moment } \\
\mu_{\text {cff }} \\
\text { (B.M.) }\end{array}$} \\
\hline & $\mathrm{C}$ & $\mathbf{H}$ & $\mathbf{N}$ & $\operatorname{Ln}$ & $\mathrm{Cl}$ & & \\
\hline $\begin{array}{l}{\left[\mathrm{La} \text { (tatd) } \mathrm{Cl}_{2}\left(\mathrm{H}_{2} \mathrm{O}\right)_{3}\right] \mathrm{Cl} \text {, }} \\
\text { Off white, } 278-82,89\end{array}$ & $\begin{array}{c}21 \cdot 00 \\
(21.04)\end{array}$ & $\begin{array}{c}4 \cdot 65 \\
(4 \cdot 71)\end{array}$ & $\begin{array}{c}10 \cdot 86 \\
(10 \cdot 90)\end{array}$ & $\begin{array}{c}27.00 \\
(27.04)\end{array}$ & $\begin{array}{c}20 \cdot 65 \\
(20 \cdot 70)\end{array}$ & $100 \cdot 2$ & - \\
\hline $\begin{array}{l}{\left[\mathrm{Pr}(\mathrm{tatd}) \mathrm{Cl}_{2}\left(\mathrm{H}_{2} \mathrm{O}\right)_{3}\right] \mathrm{Cl} \text {, }} \\
\text { Off white, } 235-38,77\end{array}$ & $\begin{array}{l}20.89 \\
(20.96)\end{array}$ & $\begin{array}{c}4 \cdot 64 \\
(4 \cdot 69)\end{array}$ & $\begin{array}{c}10 \cdot 82 \\
(10 \cdot 86)\end{array}$ & $\begin{array}{l}27 \cdot 30 \\
(27 \cdot 33)\end{array}$ & $\begin{array}{c}20 \cdot 51 \\
(20 \cdot 62)\end{array}$ & $79 \cdot 2$ & 3.58 \\
\hline $\begin{array}{l}{\left[\mathrm{Nd}(\text { tatd }) \mathrm{Cl}_{2}\left(\mathrm{H}_{2} \mathrm{O}\right)_{3}\right] \mathrm{Cl}} \\
\text { Off white, } 250-52,86\end{array}$ & $\begin{array}{c}20 \cdot 78 \\
(20 \cdot 83)\end{array}$ & $\begin{array}{c}4 \cdot 59 \\
(4 \cdot 66)\end{array}$ & $\begin{array}{c}10 \cdot 75 \\
(10 \cdot 79)\end{array}$ & $\begin{array}{l}27 \cdot 75 \\
(27 \cdot 79)\end{array}$ & $\begin{array}{c}20 \cdot 48 \\
(20 \cdot 49)\end{array}$ & $69 \cdot 1$ & $3 \cdot 64$ \\
\hline $\begin{array}{l}{\left[\mathrm{Sm}(\mathrm{tatd}) \mathrm{Cl}_{2}\left(\mathrm{H}_{2} \mathrm{O}\right) 3\right] \mathrm{Cl},} \\
\text { Off white, 255-58, }\end{array}$ & $\begin{array}{l}20 \cdot 55 \\
(20 \cdot 58)\end{array}$ & $\begin{array}{c}4 \cdot 58 \\
(4 \cdot 60)\end{array}$ & $\begin{array}{c}10 \cdot 60 \\
(10 \cdot 67)\end{array}$ & $\begin{array}{c}28 \cdot 62 \\
(28 \cdot 64)\end{array}$ & $\begin{array}{c}20 \cdot 20 \\
(20 \cdot 25)\end{array}$ & $72 \cdot 4$ & $2 \cdot 95$ \\
\hline $\begin{array}{l}{\left[\mathrm{Eu}(\mathrm{tatd}) \mathrm{Cl}_{2}\left(\mathrm{H}_{2} \mathrm{O}\right)_{3}\right] \mathrm{Cl} \text {, }} \\
\text { White, } 240-45,80\end{array}$ & $\begin{array}{c}20 \cdot 49 \\
(20 \cdot 52)\end{array}$ & $\begin{array}{c}4 \cdot 55 \\
(4.59)\end{array}$ & $\begin{array}{c}10.58 \\
(10 \cdot 63)\end{array}$ & $\begin{array}{c}28.85 \\
(28 \cdot 85)\end{array}$ & $\begin{array}{c}20 \cdot 17 \\
(20 \cdot 19)\end{array}$ & $70 \cdot 2$ & 3.06 \\
\hline $\begin{array}{l}{\left[\mathrm{Gd}(\text { tatd }) \mathrm{Cl}_{2}\left(\mathrm{H}_{2} \mathrm{O}\right)_{3}\right] \mathrm{Cl} \text {, }} \\
\text { White, } 237-40,88\end{array}$ & $\begin{array}{l}20 \cdot 28 \\
(20 \cdot 32)\end{array}$ & $\begin{array}{c}4 \cdot 49 \\
(4 \cdot 54)\end{array}$ & $\begin{array}{c}10 \cdot 50 \\
(10 \cdot 53)\end{array}$ & $\begin{array}{l}29.49 \\
(29.56)\end{array}$ & $\begin{array}{c}19.96 \\
(19.99)\end{array}$ & $58 \cdot 9$ & $8 \cdot 13$ \\
\hline $\begin{array}{l}{\left[\mathrm{Tb}(\mathrm{tatd}) \mathrm{Cl}_{2}\left(\mathrm{H}_{2} \mathrm{O}\right)_{3}\right] \mathrm{Cl}} \\
\text { Off white, } 264-68,92\end{array}$ & $\begin{array}{c}20 \cdot 19 \\
(20 \cdot 25)\end{array}$ & $\begin{array}{c}4 \cdot 48 \\
(4 \cdot 53)\end{array}$ & $\begin{array}{c}10 \cdot 42 \\
(10 \cdot 49)\end{array}$ & $\begin{array}{c}29 \cdot 70 \\
(29 \cdot 78)\end{array}$ & $\begin{array}{c}19.90 \\
(19.93)\end{array}$ & $96 \cdot 2$ & $9 \cdot 17$ \\
\hline $\begin{array}{l}{\left[\mathrm{Dy}(\mathrm{tatd}) \mathrm{Cl}_{2}\left(\mathrm{H}_{2} \mathrm{O}\right)_{3}\right] \mathrm{Cl}} \\
\text { Off white, } 252-55,92\end{array}$ & $\begin{array}{c}20 \cdot 08 \\
(20-12)\end{array}$ & $\begin{array}{c}4 \cdot 46 \\
(4 \cdot 50)\end{array}$ & $\begin{array}{c}10 \cdot 39 \\
(10 \cdot 42)\end{array}$ & $\begin{array}{c}30 \cdot 24 \\
(30 \cdot 25)\end{array}$ & $\begin{array}{c}19 \cdot 79 \\
(19.79)\end{array}$ & $89 \cdot 2$ & $10 \cdot 09$ \\
\hline $\begin{array}{l}{\left[2\left\{\mathrm{La}(\text { tatd }) \mathrm{Cl}_{2}\left(\mathrm{H}_{2} \mathrm{O}\right)_{3}\right\} \mathrm{LaCl}_{3}\right] \mathrm{Cl}_{2}} \\
\text { White, } 310-15,79\end{array}$ & $\begin{array}{l}16.93 \\
(16.99)\end{array}$ & $\begin{array}{c}3.77 \\
(3 \cdot 80)\end{array}$ & $\begin{array}{c}8.73 \\
(8.80)\end{array}$ & $\begin{array}{c}32 \cdot 70 \\
(32 \cdot 75)\end{array}$ & $\begin{array}{c}25 \cdot 00 \\
(25 \cdot 08)\end{array}$ & $203 \cdot 9$ & - \\
\hline $\begin{array}{l}{\left[2\left\{\mathrm{La}(\text { tatd }) \mathrm{Cl}_{2}\left(\mathrm{H}_{2} \mathrm{O}\right)_{3}\right\} \mathrm{PrCl}_{3}\right] \mathrm{Cl}_{2}} \\
\text { White, } 307-12,84\end{array}$ & $\begin{array}{l}16 \cdot 90 \\
(16 \cdot 96)\end{array}$ & $\begin{array}{c}3 \cdot 72 \\
(3 \cdot 79)\end{array}$ & $\begin{array}{c}8.73 \\
(8.79)\end{array}$ & & $\begin{array}{c}25 \cdot 03 \\
(25 \cdot 03)\end{array}$ & 192.4 & $3 \cdot 61$ \\
\hline $\begin{array}{l}{\left[2\left\{\mathrm{La}(\mathrm{tatd}) \mathrm{Cl}_{2}\left(\mathrm{H}_{2} \mathrm{O}\right)_{3}\right\} \mathrm{NdCl}_{3}\right] \mathrm{Cl}_{2}} \\
\text { Off white, } 315-18,78\end{array}$ & $\begin{array}{c}16.85 \\
(16 \cdot 92)\end{array}$ & $\begin{array}{c}3.75 \\
(3.78)\end{array}$ & $\begin{array}{c}8.72 \\
(8.76)\end{array}$ & & $\begin{array}{l}24 \cdot 95 \\
(24 \cdot 97)\end{array}$ & $198 \cdot 1$ & 3.69 \\
\hline $\begin{array}{l}{\left[2\left\{\mathrm{La}(\text { tatd }) \mathrm{Cl}_{2}\left(\mathrm{H}_{2} \mathrm{O}\right)_{3}\right\} \mathrm{SmCl}_{3}\right] \mathrm{Cl}_{2} \text {, }} \\
\text { White, 321-25, } 76\end{array}$ & $\begin{array}{c}16.77 \\
(16.83)\end{array}$ & $\begin{array}{c}3.72 \\
(3.76)\end{array}$ & $\begin{array}{c}8.68 \\
(8.72)\end{array}$ & & $\begin{array}{c}24 \cdot 80 \\
(24 \cdot 85)\end{array}$ & $181 \cdot 1$ & $3 \cdot 18$ \\
\hline $\begin{array}{l}{\left[2\left\{\mathrm{La}(\text { tatd }) \mathrm{Cl}_{2}\left(\mathrm{H}_{2} \mathrm{O}\right)_{3}\right\} \mathrm{EuCl}_{3}\right] \mathrm{Cl}_{2}} \\
\text { White, } 350-55,84\end{array}$ & $\begin{array}{c}16 \cdot 80 \\
(16 \cdot 82)\end{array}$ & $\begin{array}{c}3 \cdot 69 \\
(3 \cdot 76)\end{array}$ & $\begin{array}{c}8.69 \\
(8.72)\end{array}$ & & $\begin{array}{c}24 \cdot 81 \\
(24 \cdot 82)\end{array}$ & $203 \cdot 8$ & $3 \cdot 46$ \\
\hline $\begin{array}{l}{\left[2\left(\mathrm{La}(\text { tatd }) \mathrm{Cl}_{2}\left(\mathrm{H}_{2} \mathrm{O}\right)_{3}\right\} \mathrm{GdCl}_{3}\right] \mathrm{Cl}_{2}} \\
\text { Off white, } 300-05,89\end{array}$ & $\begin{array}{c}16 \cdot 71 \\
(16 \cdot 74)\end{array}$ & $\begin{array}{c}3.72 \\
(3.75)\end{array}$ & $\begin{array}{c}8.65 \\
(8.68)\end{array}$ & & $\begin{array}{c}27 \cdot 70 \\
(27 \cdot 72)\end{array}$ & $181 \cdot 1$ & $8 \cdot 29$ \\
\hline $\begin{array}{l}{\left[2\left\{\mathrm{La}(\mathrm{tatd}) \mathrm{Cl}_{2}\left(\mathrm{H}_{2} \mathrm{O}\right)_{3}\right\} \mathrm{TbCl}_{3}\right] \mathrm{Cl}_{2} \text {, }} \\
\text { White, } 312-15,85\end{array}$ & $\begin{array}{c}16.67 \\
(16.72)\end{array}$ & $\begin{array}{c}3 \cdot 70 \\
(3 \cdot 74)\end{array}$ & $\begin{array}{c}8.62 \\
(8.67)\end{array}$ & & $\begin{array}{c}24 \cdot 65 \\
(24 \cdot 68)\end{array}$ & 186.9 & $9 \cdot 29$ \\
\hline $\begin{array}{l}{\left[2\left\{\mathrm{La}(\mathrm{tatd}) \mathrm{Cl}_{2}\left(\mathrm{H}_{2} \mathrm{O}\right)_{3}\right\} \mathrm{DyCl}_{3}\right] \mathrm{Cl}_{2} \text {, }} \\
\text { White, 303-06, } 92\end{array}$ & $\begin{array}{c}16.61 \\
(16 \cdot 68)\end{array}$ & $\begin{array}{c}3.69 \\
(3.73)\end{array}$ & $\begin{array}{c}8.60 \\
(8.65)\end{array}$ & & $\begin{array}{c}24 \cdot 54 \\
(24 \cdot 61) \\
\end{array}$ & $175 \cdot 5$ & $10 \cdot 21$ \\
\hline
\end{tabular}

\subsection{Analyses and physical measurements}

The metal contents in the complexes were determined ${ }^{11}$ volumetrically by EDTA titrations using xylenol orange indicator after destroying the organic matter with aqua regia followed by concentrated $\mathrm{H}_{2} \mathrm{SO}_{4}$. Chloride was determined ${ }^{12}$ gravimetrically as $\mathrm{AgCl}$.

Carbon, hydrogen and nitrogen were analysed on a Heraeus Carlo Erba 1108 analyser. Molar conductances of the complexes were determined at room temperature in $0.001 \mathrm{M}$ 
methanol solution on WTW conductivity meter. Mass spectrum of the macrocycle was recorded on JEOL D-300C mass spectrometer. FAB mass spectra of $\left[\mathrm{Nd}(\right.$ tatd $\left.) \mathrm{Cl}_{2}\left(\mathrm{H}_{2} \mathrm{O}\right)_{3}\right] \mathrm{Cl}$ and $\left[2 / \mathrm{La}(\right.$ tatd $\left.\left.) \mathrm{Cl}_{2}\left(\mathrm{H}_{2} \mathrm{O}\right)_{3}\right\} \mathrm{NdCl}_{3}\right] \mathrm{Cl}_{2}$ were recorded on a JEOL SX 102/DA-6000 mass spectrometer/data system using Xenon as FAB gas in mnitrobenzyl alcohol as matrix. ES mass spectra of $\left[\mathrm{La}(\operatorname{tatd}) \mathrm{Cl}_{2}\left(\mathrm{H}_{2} \mathrm{O}\right)_{3}\right] \mathrm{Cl}$ and [2 $\left\{\mathrm{La}\right.$ (tatd) $\left.\left.\mathrm{Cl}_{2}\left(\mathrm{H}_{2} \mathrm{O}\right)_{3}\right\} \mathrm{LaCl}_{3}\right] \mathrm{Cl}_{2}$ were recorded on MICROMASS QUATTRO triple quadrupole by introducing methanol solution of the complex in an ESI source through a syringe pump at $0.4 \mathrm{ml}$ per hour. IR spectra of ligand and complexes were recorded in a $\mathrm{KBr}$ disc on JASCO 5300 spectrophotometer. The room temperature magnetic susceptibility was measured on a Cahn Faraday electrobalance using $\mathrm{Hg}\left[\mathrm{Co}(\mathrm{NCS})_{4}\right]$ calibrant. Electronic spectra of $\mathrm{Pr}(\mathrm{III}), \mathrm{Nd}(\mathrm{III}), \mathrm{Sm}(\mathrm{III})$ and $\mathrm{Dy}(\mathrm{III})$ complexes were recorded on a Shimadzu $160 \mathrm{~A}$ spectrophotometer in nujol mull and $10^{-2} \mathrm{M}$ methanol solution. Emission spectra of Sm(III), Eu(III) and Tb(III) complexes were recorded in solid state at liquid nitrogen temperature on a Perkin-Elmer MPF44 B fluorescence spectrophotometer.

\section{Results and discussion}

The preparation of the macrocycle has been achieved by refluxing 1,8-diamino-3,6diazaoctane and diethyl malonate in anhydrous ethanol for $120 \mathrm{~h}$. The poor yield of the macrocycle prevented the synthesis of the complexes by reacting it with the metal salt. For this reason the mononuclear complexes have been prepared through template reaction.

The complexes give satisfactory analytical results (table 1). The tatd and its complexes both mono as well as trinuclear are sensitive to moisture on prolonged exposure to the atmosphere. The complexes are soluble in DMSO and methanol and insoluble in solvents like benzene, chloroform and nitrobenzene. The mono and trinuclear complexes are found as 1:1 and 1:2 electrolytes ${ }^{13}$, respectively in methanol solution.

The molecular ion $\left(\mathrm{M}^{+}\right)$peaks at $\mathrm{m} / \mathrm{z}=477$ and 1201 in the $\mathrm{ES}$ mass spectra (figures 2 and 3) of $\left[\mathrm{La}(\right.$ tatd $\left.) \mathrm{Cl}_{2}\left(\mathrm{H}_{2} \mathrm{O}\right)_{3}\right] \mathrm{Cl}$ and $\left[2\left\{\mathrm{La}(\right.\right.$ tatd $\left.\left.) \mathrm{Cl}_{2}\left(\mathrm{H}_{2} \mathrm{O}\right)_{3}\right\} \mathrm{LaCl}_{3}\right] \mathrm{Cl}_{2}$ and at $\mathrm{m} / \mathrm{z}=482$ and 1207 in the $\mathrm{FAB}$ mass spectra (figures 4 and 5) of $\left[\mathrm{Nd}(\operatorname{tatd}) \mathrm{Cl}_{2}\left(\mathrm{H}_{2} \mathrm{O}\right)_{3}\right] \mathrm{Cl}$ and $\left[2\left\{\mathrm{La}(\right.\right.$ tatd $\left.\left.) \mathrm{Cl}_{2}\left(\mathrm{H}_{2} \mathrm{O}\right)_{3}\right\} \mathrm{NdCl}_{3}\right] \mathrm{Cl}_{2}$ indicate formation of the mono and trinuclear complexes.

In the IR spectrum of the ligand the amide $\mathrm{NH}$ streching frequency appears at $3345 \mathrm{~cm}^{-1}$ while amine $\nu(\mathrm{NH})$ appears as a distinct band at $3300 \mathrm{~cm}^{-1}$. In the complexes [ $\mathrm{Ln}$ (tatd) $\left.\mathrm{Cl}_{2}\left(\mathrm{H}_{2} \mathrm{O}\right)_{3}\right] \mathrm{Cl}$ a broad band is observed in the $3500-3200 \mathrm{~cm}^{-1}$ region which is attributed to $v(\mathrm{NH})$ of bonded $\mathrm{NH}$ moieties and $v(\mathrm{OH})$ of water. The macrocycle exhibits $\nu(\mathrm{C}=\mathrm{O})$ at $1670 \mathrm{~cm}^{-1}$ which is observed at $1660 \mathrm{~cm}^{-1}$ in the spectra of $\left[\mathrm{Ln}(\right.$ tatd $\left.) \mathrm{Cl}_{2}\left(\mathrm{H}_{2} \mathrm{O}\right)_{3}\right] \mathrm{Cl}$ complexes. The lowering in $\nu(\mathrm{C}=\mathrm{O})$ occurs due to shifting of electron density towards nitrogens which is bonded to $\mathrm{Ln}^{3+}$ ions. The lowering of the $\nu(\mathrm{C}=\mathrm{O})$ band in trinuclear complexes is observed almost in the same region as in that of the parent complex. It is due to bonding of the carbonyl oxygen to the metal ions. The simultaneous bonding of the ring nitrogens and the exo oxygens with the metal ions cause shifting of the electron density in the opposite direction and therefore, no change in the position of $\boldsymbol{v}(\mathrm{C}=\mathrm{O})$ is observed. The coordinated ${ }^{14}$ nature of water is indicated from the presence of bands at $685-680$ and $565-560 \mathrm{~cm}^{-1}$ due to $\rho_{r}\left(\mathrm{H}_{2} \mathrm{O}\right)$ and $\rho_{w}\left(\mathrm{H}_{2} \mathrm{O}\right)$ respectively.

The room temperature magnetic moments of complexes (table 1) show very little deviation from the van Vleck values ${ }^{15}$ implying the participation of $4 \mathrm{f}$ electrons in 


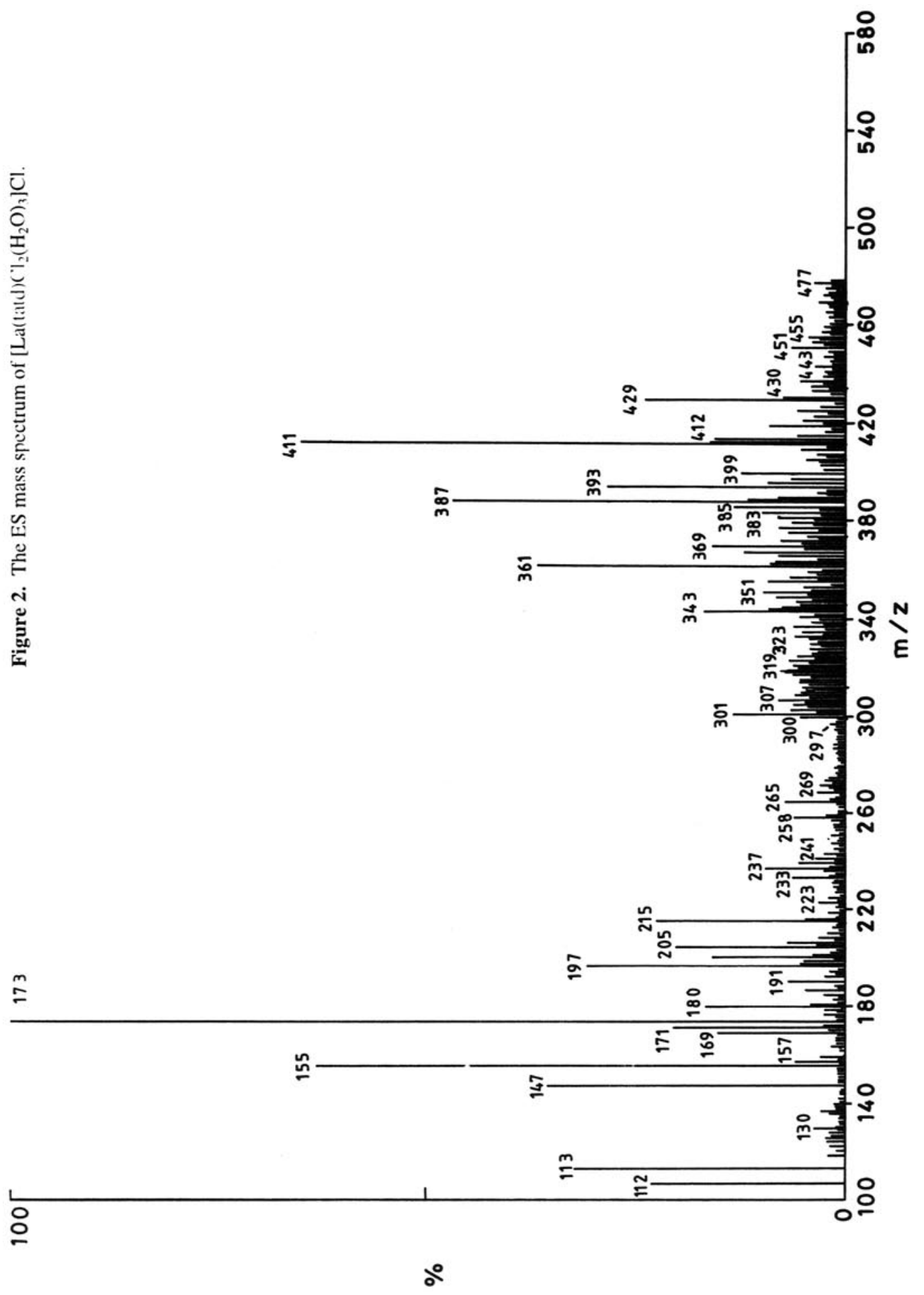




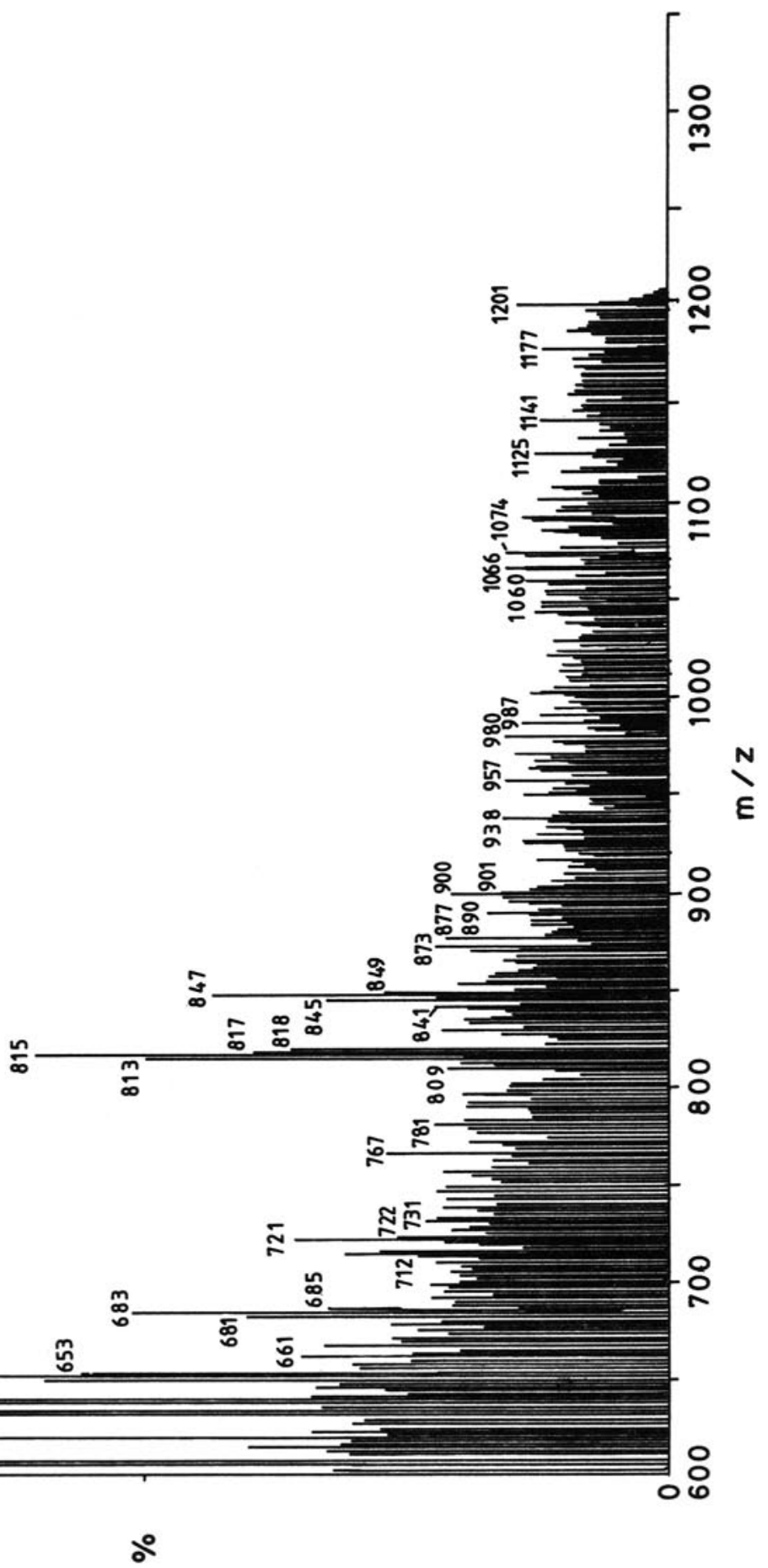




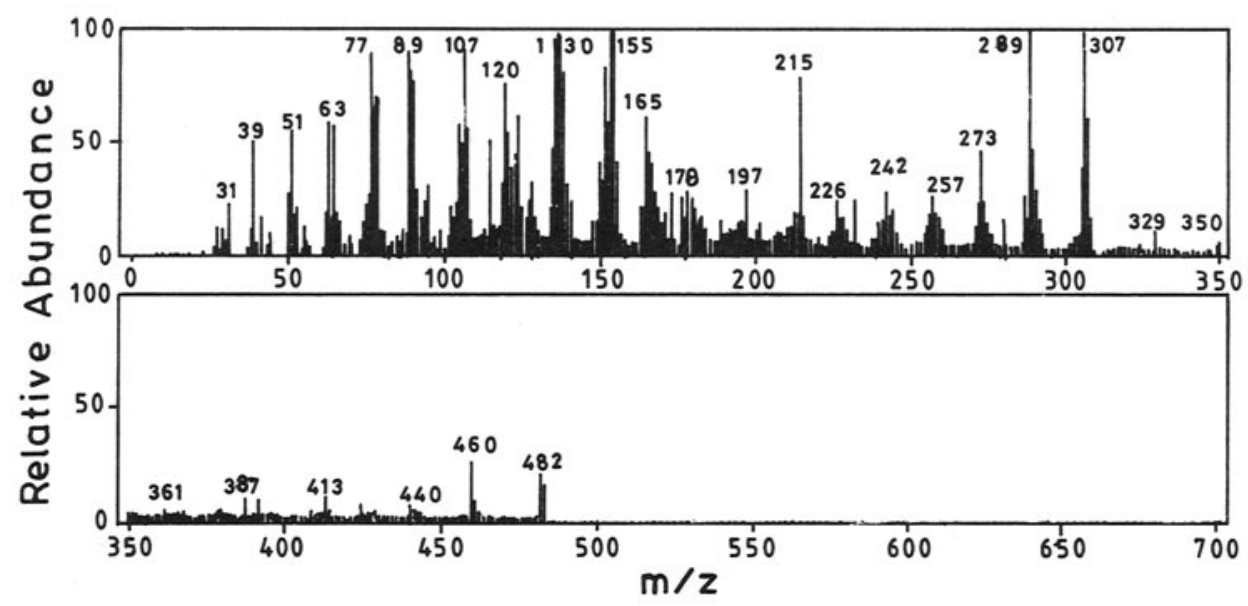

Figure 4. Mass spectrum of $\left[\mathrm{Nd}(\operatorname{tatd}) \mathrm{Cl}_{2}\left(\mathrm{H}_{2} \mathrm{O}\right)_{3}\right] \mathrm{Cl}$.

bonding. The slightly higher magnetic moments in case of $\mathrm{Sm}$ (III) and Eu(III) complexes are due to temperature dependent magnetism on account of low $\mathrm{J}-\mathrm{J}$ separation ${ }^{16}$. In trinuclear complexes the magnetic moments are almost similar to [Ln(tatd) $\left.\mathrm{Cl}_{2}\left(\mathrm{H}_{2} \mathrm{O}\right)_{3}\right] \mathrm{Cl}$ complexes. The paramagnetism is only due to one of the metal ions like $\mathrm{Pr}^{3+}, \mathrm{Nd}^{3+}, \mathrm{Sm}^{3+}, \mathrm{Eu}^{3+}, \mathrm{Gd}^{3+}, \mathrm{Tb}^{3+}$ and $\mathrm{Dy}^{3+}$. The lanthanum compound is diamagnetic as expected.

The absorption spectra of $\operatorname{Pr}($ III), Nd(III) Sm(III) and Dy(III) complexes show red shift in the bands compared to aqua metal ion ${ }^{17}$ indicating metal ligand interaction ${ }^{18}$. The spectra were analysed and various spectral parameters viz, nephelauxetic ratio $(\beta)$, bonding $\left(b^{1 / 2}\right)$, Sinha $(\delta \%)$ and covalency $(\eta)$ have been calculated from the solid state spectra. The $\beta$ values are less than unity and $b^{1 / 2}$ and $\delta \%$ values are positive. They indicate weak covalent bonding between metal and ligand ${ }^{19}$. The band at $17321 \mathrm{~cm}^{-1}$ in the spectrum of the $\mathrm{Nd}$ (III) complex is assigned to the hypersensitive transitions ${ }^{4} \mathrm{I}_{9 / 2} \rightarrow{ }^{4} \mathrm{G}_{5 / 2},{ }^{2} \mathrm{G}_{7 / 2}$. The nujol mull and methanol solution spectra of $\operatorname{Pr}$ (III), Nd (III), Sm(III) and Dy(III) complexes show similar profiles in position and shape. It may, therefore, be inferred that there is no change in coordination environment due to solvation effect $^{20}$.

The absorption intensity presented as oscillator strengths have been calculated by using the literature procedure ${ }^{20,21}$. The oscillator strengths corresponding to all the observed bands of $\left[\mathrm{Nd}(\operatorname{tatd}) \mathrm{Cl}_{2}\left(\mathrm{H}_{2} \mathrm{O}\right)_{3}\right] \mathrm{Cl}$ are larger than those reported for the aqua ions ${ }^{22}$. The increase in the oscillator strength values is attributed to interaction of Nd(III) ion with ligand leading to a larger covalency of the metal-ligand bonding. The larger increase in the oscillator strength for the hypersensitive transition is due to the dynamic coupling between f-electron quadrupole moment and polarizability of the ligand in complex $^{23}$.

In trimetallic complexes La(III) does not show $f-f$ transitions as it has $4 f^{0}$ configuration. So in these complexes the observed absorption bands are due to $f-f$ transitions of the metal ions other than $\mathrm{La}^{3+}$. The bands are observed at lower wave numbers in the spectra of $\left[\left\{2 \mathrm{La}(\operatorname{tatd}) \mathrm{Cl}_{2}\left(\mathrm{H}_{2} \mathrm{O}\right)_{3}\right\} \mathrm{NdCl}_{3}\right] \mathrm{Cl}_{2}$ and $\left[2\left\{\mathrm{La}\right.\right.$ (tatd) $\left.\mathrm{Cl}_{2}\left(\mathrm{H}_{2} \mathrm{O}\right)_{3}\right\}$ $\mathrm{PrCl}_{3} \mathrm{Cl}_{2}$ compared to the corresponding absorption in aqua metal ions ${ }^{17}$, indicating 


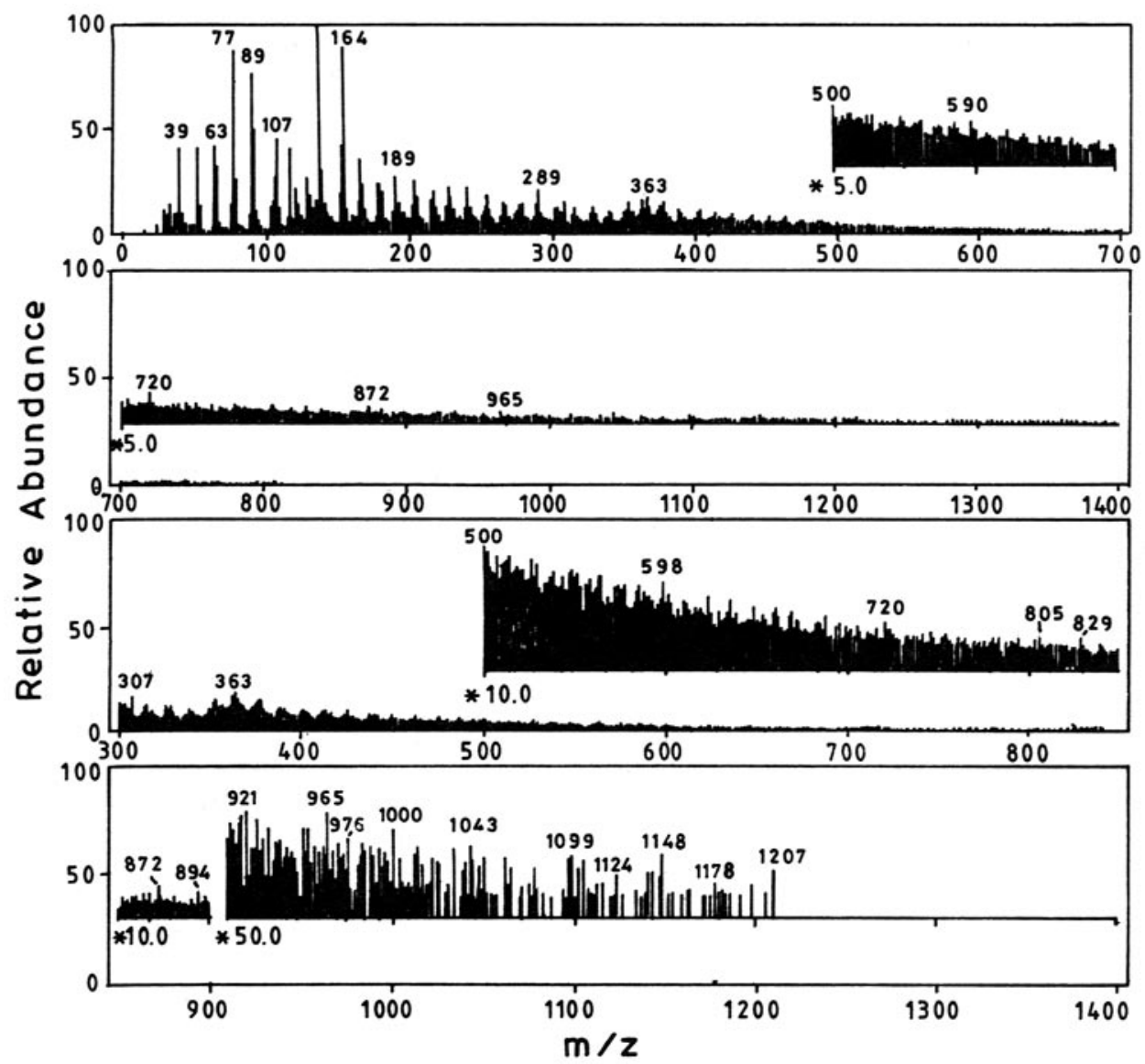

Figure 5. Mass spectrum of $\left[2\left\{\mathrm{La}(\mathrm{tatd}) \mathrm{Cl}_{2}\left(\mathrm{H}_{2} \mathrm{O}\right)_{3}\right\} \cdot \mathrm{NdCl}_{3}\right] \mathrm{Cl}_{2}$.

metal-ligand interaction ${ }^{18}$. The $\beta$ values are less than unity and $b^{1 / 2}$ and $\delta$ are positive. They indicate weak covalent bonding between the metal and ligand ${ }^{19}$.

Emission spectrum (figure 6) of the complex [Eu(tatd) $\left.\mathrm{Cl}_{2}\left(\mathrm{H}_{2} \mathrm{O}\right)_{3}\right] \mathrm{Cl}$ shows strong emission lines when excited with $350 \mathrm{~nm}$ radiation at liquid nitrogen temperature (LNT). The spectrum shows lines at 590,610,650 and $692 \mathrm{~nm}$ which are attributed to the ${ }^{5} D_{0} \rightarrow{ }^{7} F_{1},{ }^{5} D_{0} \rightarrow{ }^{7} F_{2},{ }^{5} D_{0} \rightarrow{ }^{7} F_{3}$ and ${ }^{5} D_{0} \rightarrow{ }^{7} F_{4}$ transitions, respectively. The ${ }^{5} D_{0} \rightarrow{ }^{7} F_{0}$ transition is absent whereas ${ }^{5} D_{0} \rightarrow{ }^{7} F_{3}$ transition appears as a weak band. The higher intensity of the electric dipole allowed transition $\left({ }^{5} D_{0} \rightarrow{ }^{7} F_{2}\right)$, as compared to magnetic dipole allowed transition ${ }^{5} D_{0} \rightarrow{ }^{7} F_{1}$, suggests low symmetry for the complex ${ }^{24}$ and absence of the inversion centre. The appearance of ${ }^{5} D_{0} \rightarrow{ }^{7} F_{1}$ as doublet and of the ${ }^{5} D_{0} \rightarrow{ }^{7} F_{2}$ transition as a singlet is indicative of $D_{3 h}$ symmetry ${ }^{25}$. The trinuclear complex [2\{ $\mathrm{La}($ tatd $\left.\left.)\left(\mathrm{H}_{2} \mathrm{O}\right)_{3} \mathrm{Cl}_{2}\right\} \mathrm{EuCl}_{3}\right] \mathrm{Cl}_{2}$ does not fluoresce. This may be due to internal quenching through strong coupling of the ions with the crystal forces. Therefore, no conclusions could be drawn regarding the symmetry around the metal ions. 


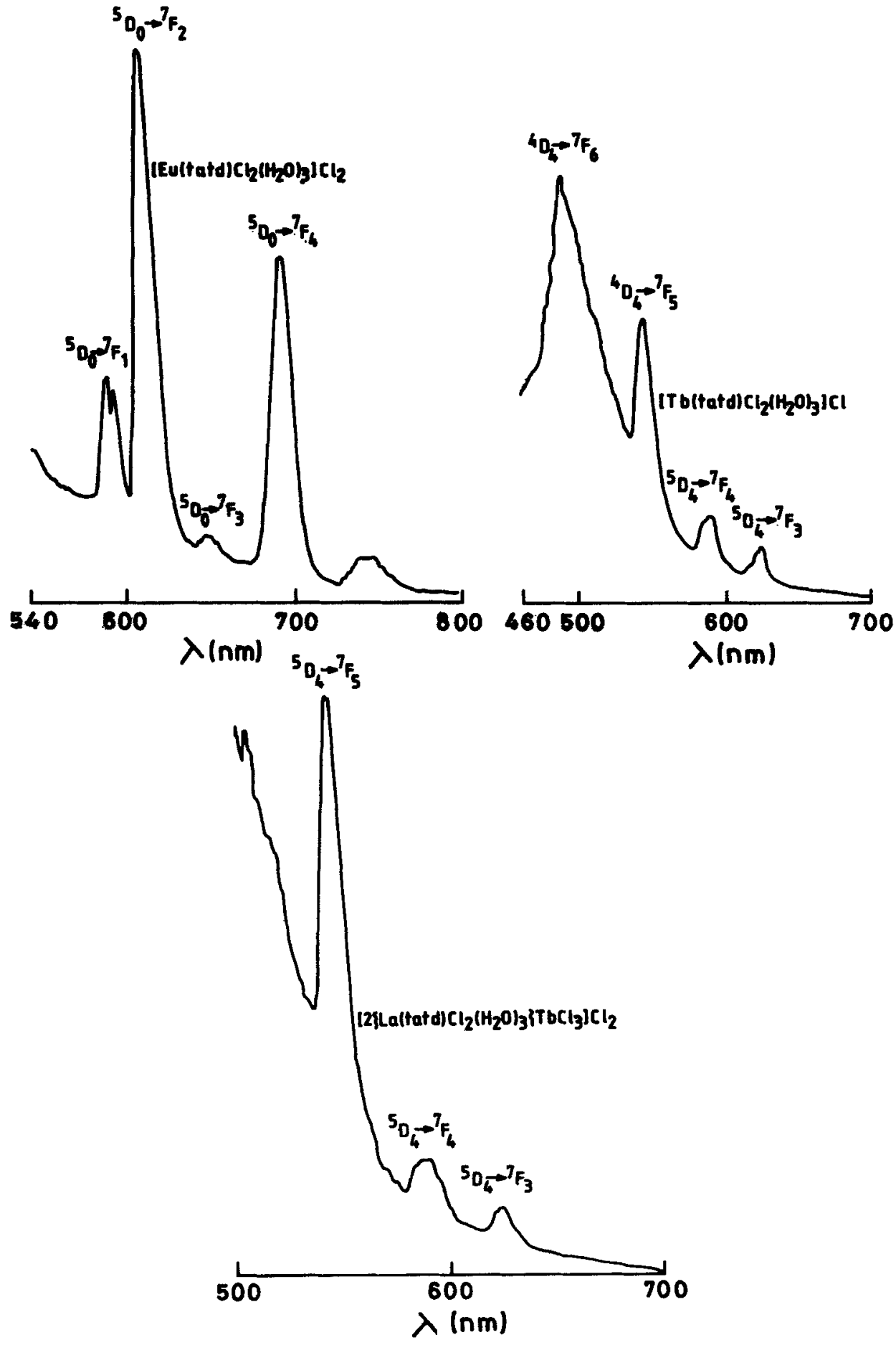

Figure 6. The emission spectra of $\mathrm{Eu}(\mathrm{III})$ and $\mathrm{Tb}(\mathrm{III})$ complexes. 


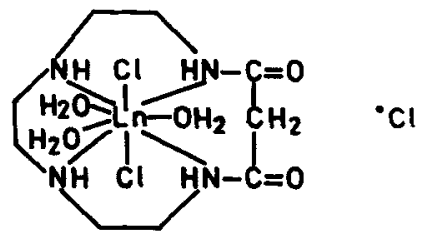

Figure 7. Tentative structure of mononuclear complexes.

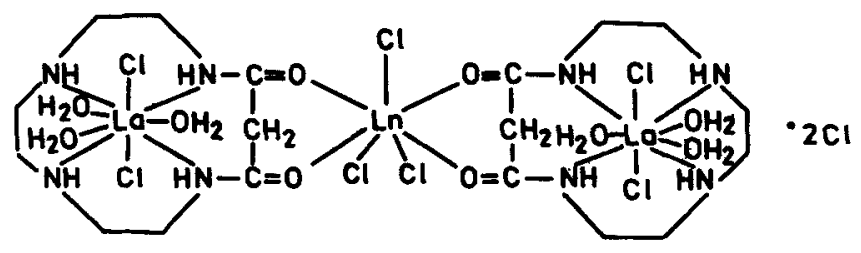

Figure 8. Tentative structure of trinuclear complexes.

The spectrum of $\mathrm{Tb}(\mathrm{III})$ complex shows strong emission lines. The ${ }^{5} D_{4} \rightarrow{ }^{7} F_{5}$ and ${ }^{5} D_{4} \rightarrow{ }^{7} F_{6}$ are observed as the most populated transitions at 548 and $492 \mathrm{~nm}$, respectively. The transitions observed at 588 and $624 \mathrm{~nm}$ due to ${ }^{5} D_{4} \rightarrow{ }^{7} F_{4}$ and ${ }^{5} D_{4} \rightarrow{ }^{7} F_{3}$, respectively, are less intense. The transitions are broad without any splitting and suggest a high symmetry for the electrostatic field around terbium (III) ${ }^{26}$. The trinuclear complex $\left[2\left(\mathrm{La}\right.\right.$ (tatd) $\left.\mathrm{Cl}_{2}\left(\mathrm{H}_{2} \mathrm{O}\right)_{3} \mathrm{TbCl}_{3}\right] \mathrm{Cl}_{2}$ shows emission lines at 523,585 and $623 \mathrm{~nm}$ which are attributed to the ${ }^{5} D_{4} \rightarrow{ }^{7} F_{5},{ }^{5} D_{4} \rightarrow{ }^{7} F_{4}$ and ${ }^{5} D_{4} \rightarrow{ }^{7} F_{3}$ transitions, respectively. The ${ }^{5} D_{4} \rightarrow{ }^{7} F_{5}$ is most populated transition. The transitions ${ }^{5} D_{4} \rightarrow{ }^{7} F_{4}$ and ${ }^{5} D_{4} \rightarrow{ }^{7} F_{3}$ are less intense. These data suggest higher symmetry of the crystal field around $\mathrm{Tb}(\mathrm{III})^{26}$.

Both the complexes [Sm(tatd) $\left.\mathrm{Cl}_{2}\left(\mathrm{H}_{2} \mathrm{O}\right)_{3}\right] \mathrm{Cl}$ and $\left[2\left\{\mathrm{La}(\mathrm{tatd})\left(\mathrm{H}_{2} \mathrm{O}\right)_{3} \mathrm{Cl}_{2}\right\} \mathrm{SmCl}_{3}\right] \mathrm{Cl}_{2}$ do not either fluoresce or fluoresce very weakly even at liquid nitrogen temperature. This may be due to internal quenching through strong coupling of the metal ions with the crystal forces ${ }^{24}$. Therefore no conclusions could be drawn regarding the symmetry around the metal ion.

Based on the above results the structure proposed for the mono and trinuclear complexes are shown in figures 7 and 8 , respectively.

\section{Acknowledgement}

We thank the Head of the Chemistry Department, Banaras Hindu University, for providing laboratory facilities. One of us (VLS) thanks Banaras Hindu University for providing research fellowship. Recording of mass spectra and $\mathrm{C}, \mathrm{H}$, and $\mathrm{N}$ analyses were done at the Central Drug Research Institute, Lucknow.

\section{References}

1. Brucher E, Cortes S, Chavez F and Sherry A D 1991 Inorg. Chem. 302092

2. Inoue M B, Villegas C A, Asano K, Nakamura M, Inoue M and Fernando Q 1992 lnorg. Chem. 312480 
3. Radecka Paryzek W 1981 Inorg. Chim. Acta 52261

4. Bombieri G, Benetollo F, Pollo A, De Cola L. Hawkins W T and Vallarino L M 1989 Polyhedron 82157

5. Shakir M, Nasman O S M, Mohamed A K and Varkey S P 1996 Polyhedron 151283

6. Morrow J R, Buttrey L A, Shelton V M and Berback K A 1992 J. Am. Chem. Soc. 1141903 and references therein

7. Miller J S, Epstein A J and Reiff W M 1988 Chem. Rev. 88201

8. Kahn O, Pei Y, Verdanger M, Renord J P and Sletten J 1988 J. Am. Chem. Soc. 110782

9. Ganeschi A, Gatteschi D, Sessoli R and Rey P 1989 Acc. Chem. Res. 22392

10. Tabushi H, Okino H and Kurodo Y 1976 Tetrahedron Lett. 4339

11. Lyle S J and Rahman M Md 1963 Talanta 101177

12. Vogel I A 1969 A text book of quantitative inorganic analysis 3rd edn. (New York: Longman)

13. Geary W J 1971 Coord. Chem. Rev. 781

14. Nakamoto $\mathrm{K} 1986$ Infrared and Rainan spectra of inorganic and coordination compounds (Wiley Interscience: New York) p 227

15. Van Vleck J H and Frank A 1929 Phys. Rev. 341994

16. Figgis B N and Lewis J 1965 Techniques of inorganic chemistry (Interscience: New York) 4 p 137

17. Carnall W T, Fields P R and Rajnak K J 1968 J. Chem. Phys. 494424

18. Schaffer C E and Jorgensen C K 1958 J. Inorg. Nucl. Chem. 8143

19. Tandon S P and Mehta P C 1970 J. Chem. Phys. 524896

20. Karraker D G 1968 Inorg. Chem. 7473

21. Karraker D G 1967 Inorg. Chem. 61863

22. Iftikhar K 1987 Inorg. Chim. Acta 129261

23. Mason S F, Peacock R D and Stewart B 1975 Mol. Phys. 301829

24. Blasse G 1979 Handbook of physics and chemistry of rare-earths (eds) K H Gschneidner Jr and L Eyring (North Holland: Amsterdam) vol. 4 chap. 34

25. Blasse G, Bril A and Nieuwport W C 1966 J. Phys. Chem. Solids 271587

26. Musumeci A, Bonomo R P, Cucinotta V and Seminara A 1982 Inorg. Chim. Acta 59133 